\title{
A meta-analysis of the efficacy of over-the-counter nicotine replacement
}

\author{
J R Hughes, S Shiffman, P Callas, J Zhang
}

Tobacco Control 2003;12:21-27

See end of article for authors' affiliations

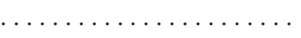

Correspondence to: John R Hughes, MD, University of Vermont Department of Psychiatry, 38 Fletcher Place,

Burlington, VT 05401 ,

USA;

john.hughes@uvm.edu

Received 20 March 2002. Accepted

4 December 2002
Objective: To determine whether over-the-counter (OTC) nicotine replacement therapy (NRT) is pharmacologically efficacious, whether it produces abstinence rates similar to those in prescription settings, and to estimate the long term (that is, greater than six month) abstinence rate with OTC NRT.

Method: Systematic literature review.

Data sources: Medline, Psych Abstracts, bibliographies, requests of scientists.

Study selection: Studies comparing OTC NRT versus OTC placebo or studies comparing OTC NRT versus prescription NRT that reported abstinence rates and for which a full study report was available. Data extraction: Two of the authors independently reviewed studies and compared results.

Data synthesis: Meta-analysis was performed by first testing for homogeneity across studies, then combining odds ratios (ORs) weighting by inverse variance and proportions weighting by study sample size.

Results: One OTC NRT versus OTC placebo nicotine gum study was excluded due to small sample size and different setting. The four remaining studies were randomised trials of nicotine versus placebo patch with ORs of 2.1-3.2. These outcomes were homogenous and when combined resulted in an OR favouring NRT of 2.5 (95\% confidence interval (CI) 1.8 to 3.6). Among the two randomised and two non-randomised trials of OTC NRT versus prescription NRT, one small study had an OR of 0.3 , two others had ORs of 1.0 and 1.4, and a fourth study had an OR of 3.6. These results were not homogenous; however, when combined via a random effects model the estimated OR was not less than 1.0-that is, OR $1.4(95 \% \mathrm{Cl} 0.6$ to 3.3). The long term (that is, greater than six months) quit rates for OTC NRT was $1 \%$ and $6 \%$ in two studies and $8-11 \%$ in five other studies. These results were not homogenous; however, when combined the estimated OR was $7 \%(95 \% \mathrm{Cl} 4 \%$ to $11 \%)$.

Conclusions: OTC NRT is pharmacologically efficacious and produces modest quit rates similar to that seen in real world prescription practice.
M eta-analyses of over 100 randomised trials conclude nicotine replacement therapy (NRT; nicotine gum, inhaler, patch, nasal spray and lozenge/microtab) approximately double the rates of long term smoking cessation. $^{1{ }^{2}}$ In almost all of these trials, some degree of behavioural support was provided. Consistent with this, in almost all countries, NRT was initially available only via prescription, in part to insure the provision of behavioural support. However, it soon became clear that most smokers about to quit were not willing to see a physician ${ }^{3}$ nor attend a behavioural programme. ${ }^{4}$ Thus, NRTs became available without a prescription. In some countries (for example, Germany) they are available by request from a pharmacist-that is, "behind-the-counter"; in other countries (for example, USA) they are generally available and sold "over-the-counter" (OTC).

Prior articles have voiced both concerns and reassurances about the safety, abuse liability, and unintended effects of OTC NRT. ${ }^{15-17}$ The current analysis focuses on the efficacy of OTC NRT.

One reason to question the efficacy of OTC NRT is the common belief in the treatment of non-nicotine drug dependencies that every patient should receive psychosocial therapy and some should also receive medication. ${ }^{18}{ }^{19}$ In fact, the initial package insert for prescription NRT in the USA stated NRT "should be used as a part of a comprehensive behavioural smoking cessation program". However, recent reviews and meta-analyses conclude the ability of NRT to increase quit rates over placebo is independent of the presence of a concomitant behavioural programme. ${ }^{120}$ This would suggest NRT should be effective in an OTC setting. In fact, the rates of successful quitting among those who made an attempt is similar among smokers using NRT before and after NRT was switched to OTC. ${ }^{1321}$

Another reason to doubt efficacy is that OTC status may make it too easy to access treatment-that is, ambivalent smokers may use OTC NRT, fail because of low motivation, blame the NRT, and discard a treatment that would have been efficacious if they had been more motivated. However, unwillingness to see a physician is influenced by many variables other than motivation-for example, past experiences, geography, money, and insurance plan. We are unaware of studies comparing the motivation of OTC versus prescription NRT users.

A final reason to doubt efficacy is that physician's advice may be needed to insure compliance with medication. However, most surveys suggest physicians do not spend time urging compliance ${ }^{22}$ and the two existing surveys of OTC use $^{23} 24$ reported a duration of use of OTC NRT that is similar to that for physician assisted use. ${ }^{22} 25$

Concerns about the efficacy of OTC NRT can be divided into three questions: whether (a) it is efficacious (improves long term abstinence rates over placebo); (b) its efficacy is substantially smaller than that seen with physician assisted NRT; and (c) its efficacy is so low as to not be meaningful. To provide a quantitative answer to the above concerns, we undertook a meta-analysis of OTC trials that either tested OTC

Abbreviations: $\mathrm{Cl}$, confidence interval; $\mathrm{NRT}$, nicotine replacement therapy; OTC, over-the-counter; OR, odds ratio 
NRT versus OTC placebo, or tested OTC NRT versus prescription NRT. To our knowledge, the only prior metaanalysis of OTC NRT was that of the US Public Health Services (USPHS) guidelines which compared active versus placebo NRT. ${ }^{1}$ Based on three studies, this guideline reported an odds ratio of 1.8 with a $95 \%$ confidence interval (CI) of 1.2 to 2.8 and point prevalence quit rates of $12 \%$ for active NRT and $7 \%$ for placebo.

\section{METHODS}

To locate studies, we searched Medline and Psychlit via computer, bibliographies of NRT articles, and meeting abstracts. We also sent inquiries to tobacco/nicotine scientists and pharmaceutical companies. After the meta-analyses were conducted, a draft of the manuscript was sent to authors of included studies for corrections and comments.

Inclusion criteria were prospective trials of either OTC NRT versus placebo or of OTC NRT versus prescription NRT for smoking cessation that reported abstinence rates. To prevent exclusion bias, the trials did not need to be randomised trials and did not need to be published trials if a full manuscript describing the study in sufficient detail was available.

We located five controlled trials of OTC NRT versus placebo $^{27-31}$ and four trials of OTC NRT versus prescription NRT. $^{32-34}$ Three completed trials were not included because a full manuscript was not available at the time of our analyses. One of these was a study of OTC inhaler versus OTC placebo ${ }^{35}$; another was OTC patch versus placebo done in Japan ( $M$ Nakamura, personal communication, 24 May 2001) and one was OTC gum under different price conditions. ${ }^{36}$ We are aware of two other trials currently underway: one compares nicotine gum under OTC, medical management, and group treatment conditions, ${ }^{37}$ and the other compares nicotine inhaler in OTC versus prescription conditions (B Korberly, personal communication, 8 January 2002).

\section{Methodological issues}

Readers should be aware of several methodological issues in the conduct of OTC NRT trials. Some OTC trials have subjects attend several assessment visits. Some have thought these assessments themselves may increase quit rates. ${ }^{8}{ }^{15}$ One possible line of evidence for this comes from studies showing daily self monitoring decreases the number of cigarettes/day ${ }^{38}$; however, we are unaware of any studies showing that attending visits increases abstinence rates. A second possible line of evidence is that meta-analyses have found quit rates increase with the amount of contact ${ }^{1}$; however, these meta-analyses were measuring therapeutic contact, not assessment contact.

For ethical reasons, OTC NRT trials that include placebo arms provide medication free of charge. Provision of free medications increases quit rates compared to requiring subjects to pay for $\mathrm{NRT}^{313940}$; thus, the OTC NRT versus OTC placebo studies likely overestimate real world quit rates.

Some OTC trials include biochemical verification. However, many of these have difficulty in motivating subjects to return for assessments or biochemical verification because subjects in OTC trials have little contact or relationship with study personnel and thus little investment in the study. Other OTC trials do not include biochemical verification and cite recent reviews that conclude trials in which there is little face-to-face contact (such as OTC trials) have a falsification rate so low that biochemical verification is not necessary. ${ }^{41} 42$

The above concerns (assessments, payment, biochemical verification) may change absolute quit rates. It is unclear (and many believe unlikely ${ }^{41}{ }^{42}$ that these problems would be sufficiently more frequent in one group to influence group differences. In fact, several authors believe such external conditions set the base rate of quitting (but not active/placebo differences) and that NRT has a multiplicative effect on that base rate. ${ }^{120}$
A final issue is not restricted to OTC trials. In the tobacco treatment field, the term "efficacy" has often been applied to absolute quit rates. In most other fields, efficacy refers to active versus control differences, measured by statistics such as the odds ratio (OR). For this article, efficacy will refer only to measures of active versus placebo differences.

\section{Overview of analyses}

The first meta-analysis examines pharmacological efficacy via studies that directly compared OTC NRT with OTC placebo. The second meta-analysis examines comparability of OTC and prescription efficacy via studies that directly compared OTC NRT and prescription NRT. The third meta-analysis estimates the actual abstinence rate with OTC NRT by combining the data from all the OTC NRT groups available. For the comparison of OTC NRT with OTC placebo and OTC NRT with prescription NRT, homogeneity of ORs across studies was tested using the $\chi^{2}$ homogeneity test statistic. ${ }^{43}$ The pooled OR was estimated by first computing the natural logarithm of each OR, then combining using the inverse variance of the log ORs as weights; 95\% confidence intervals (CIs) were computed using the estimated standard error of the log common OR, and results were returned to OR scale by computing the antilogarithm of the point estimate and CI end points. The overall proportion of OTC NRT users abstinent was estimated pooling by study sample size, with a $\chi^{2}$ test of homogeneity. Sources of heterogeneity across studies were analysed by partitioning the $\chi^{2}$ statistic as described by Fleiss. ${ }^{43}$ When significant heterogeneity was present, a random effects model was used in order to include the estimated between study variance in the analysis. ${ }^{44}$

\section{RESULTS}

\section{OTC NRT versus OTC placebo studies}

The OTC NRT versus OTC placebo trials were all randomised, parallel groups studies in which subjects received free product. The first study by Schneider et $a^{29}$ was the only placebo controlled OTC study of nicotine gum. The study was published in 1983, 14 years before the next study and had a much smaller sample size $(\mathrm{n}=36)$ than other OTC studies. In addition "laboratory changes" resulted in a notably uneven distribution of subjects to nicotine and placebo groups ( $13 \mathrm{v}$ 23). Finally, when contacted, the author believed that this study did not represent an OTC setting because of the amount of contact (N Schneider, personal communication, 20 September 2001). For these reasons, we decided not to include the Schneider et al study ${ }^{29}$ in the meta-analysis.

In the 1990s, four randomised, double blind trials with large sample sizes $(\mathrm{n}=278-802)$ tested active versus placebo patch (table 1). The Davidson et al trial ${ }^{28}$ was similar to the other studies except it was conducted in four shopping malls. The Hays et al study $y^{31}$ was conducted at five study sites including private offices or storefronts. The study first randomised subjects into one of two trials: (1) a randomised, two group OTC NRT versus OTC placebo trial in which subjects received free patches; or (2) a one group, open label trial in which subjects had to pay for patches. We did not use the open label trial in the meta-analysis because it did not have a control group.

The Shiffman et al study ${ }^{27}$ was conducted at eight non-clinical sites. Like the prior studies, subjects received free patches, but unlike the others the study did not include a six month follow up (the last follow up was 10 weeks) nor require a minimum number of cigarettes/day for study entry. The Sonderskov et al study ${ }^{30}$ recruited smokers about to purchase their first patch at one of 42 Danish pharmacies by offering them free patches if they entered the study. The pharmacies recruited $91 \%$ of eligible smokers. Pharmacists initially instructed subjects on patch use; whether they provided advice and counselling was not stated. Smokers of more than 20 cigarettes/day were randomly assigned to $21 \mathrm{mg} /$ day or 
Table 1 Studies of OTC NRT versus OTC placebo

\begin{tabular}{llllllll}
\hline Study & Product & $n$ & Cigs/day & Visits & $\begin{array}{l}\text { Follow up } \\
\text { (months }\end{array}$ & Outcome & $\begin{array}{l}\text { Biochemical } \\
\text { variation }\end{array}$ \\
\hline Davidson et $a^{28}$ & Patch & 802 & $\geqslant 20$ & 10 & 6 & $\begin{array}{l}\text { Repeated } \\
\text { point } \\
\text { prevalence }\end{array}$ & Yes \\
Hays et $a^{\beta 1}$ & Patch & 643 & $\geqslant 15$ & 8 & 6 & $\begin{array}{l}\text { Continuous } \\
\text { abstinence }\end{array}$ & No \\
Shiffman et $a^{27}$ & Patch & 567 & $>0$ & 3 & 2.5 & $\begin{array}{l}\text { Prolonged } \\
\text { abstinence }\end{array}$ & Yes \\
Sonderskov et $a^{\beta 0}$ & Patch & $278 \geqslant 20$ & 3 & 6 & $\begin{array}{l}\text { Repeated } \\
\text { point } \\
\text { prevalence }\end{array}$ & No \\
\hline
\end{tabular}

Table 2 Results of OTC NRT versus OTC placebo

\begin{tabular}{llll}
\hline Study & $\begin{array}{l}\text { Abstinent } \\
\text { with NRT }\end{array}$ & $\begin{array}{l}\text { Abstinent with } \\
\text { placebo }\end{array}$ & OR $(95 \% \mathrm{Cl})$ \\
\hline Davidson et $a^{28}$ & $33 / 401$ & $16 / 401$ & $2.2(1.2$ to 4.0$)$ \\
Hays et $a^{\beta 1}$ & $18 / 321$ & $9 / 322$ & $2.1(0.9$ to 4.7$)$ \\
Shiffman et $a^{27}$ & $43 / 283$ & $15 / 284$ & $3.2(1.7$ to 5.9$)$ \\
Sonduskov et $a^{\beta 0}$ & $15 / 136$ & $6 / 142$ & $2.8(1.1$ to 7.5$)$ \\
\hline
\end{tabular}

placebo, but smokers of less than 20 cigarettes/day were assigned to the $14 \mathrm{mg}$ dose or placebo. Finally, this study was the only behind-the-counter (that is, not OTC) trial in our analysis. (For brevity we still use the term OTC to describe the studies in this article because six of the seven trials were true OTC trials).

\section{OTC NRT versus OTC placebo meta-analysis}

The four randomised trials of OTC NRT versus OTC placebo we entered in the meta-analysis were all nicotine patch trials in which subjects received free medication. Studies varied in whether repeated point prevalence, continuous abstinence or prolonged abstinence was reported. A recent re-analysis ${ }^{45}$ and meta-analysis ${ }^{46}$ suggests that these measures produce similar absolute quit rates and almost identical ORs but differ from simple point prevalence outcomes. ${ }^{46}$ Since repeated point prevalence was the most common outcome, when available this was used for our meta-analyses. When repeated point prevalence was not available, continuous abstinence or prolonged abstinence was used. Exploratory meta-analyses confirmed that outcomes did not differ significantly when different abstinence definitions were used. In each study, we abstracted the fraction of subjects abstinent at the last follow up. The last follow up was six month post-cessation for three studies and 10 weeks for one study (table 1 ).

The ORs for the four patch studies were 2.1, 2.2, 2.8, and 3.2 and three of the four CIs did not overlap with 1.0 (table 2, fig 1). The study with the highest OR was the study with the 10 week follow up. The test for homogeneity of results across studies was negative $(p=0.8)$ indicating the results were homogenous enough to be aggregated. The overall OR from the meta-analysis was 2.5 (95\% CI 1.8 to 3.6), which was significantly greater than 1.0 , indicating OTC NRT was efficacious compared to placebo.

\section{Studies of OTC NRT versus prescription NRT}

The methodologies of the OTC NRT versus prescription NRT studies were similar to that of the OTC NRT versus OTC placebo studies, except two of the trials were not randomised trials and in all four trials subjects purchased both OTC and prescription product (table 3 ). The Korberly study ${ }^{33}$ was a large $(\mathrm{n}=3235)$ randomised trial of a nicotine patch that used 10 non-medical offices and 13 physician offices for the OTC and

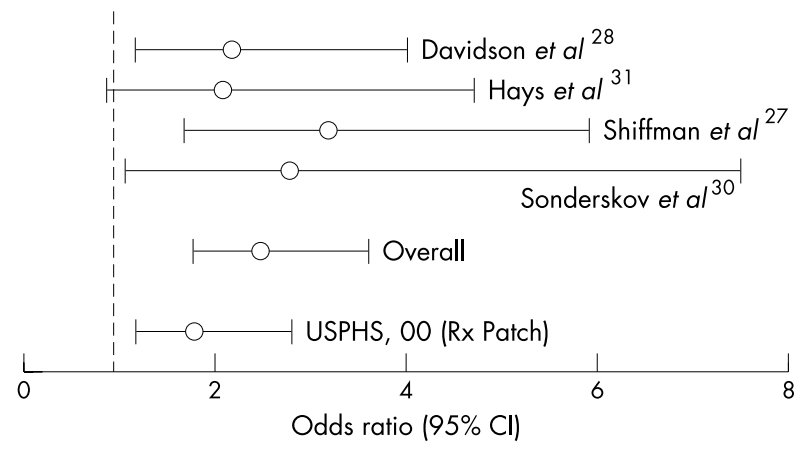

Figure 1 Odds ratio and $95 \%$ confidence interval for OTC NRT versus OTC placebo studies using intent-to-treat analysis. Note $\mathrm{x}$ axis is not in log coordinates.

prescription settings. Unlike the other studies, this study did not use an intent-to-treatment sample but rather used those that had ever used patch as the sample. The Leischow study ${ }^{34}$ was a one site, randomised, parallel groups study of a nicotine patch. Its sample size was large $(\mathrm{n}=300)$ but was only $10 \%$ as large as the other very large studies of OTC versus prescription. The prescription condition required subjects to see a physician who implemented the National Cancer Institute's 4 A's smoking cessation protocol, ${ }^{47}$ instructed subjects in use of the patch, and answered any questions. This occurred at the baseline and two week follow up visits. Abstinence rates were low (for example, six months continuous abstinence $=0-3 \%$ ) and were hypothesised to be related to low compliance, high dropout rates, low amount of physician advice, few required visits, and low patch use due to cost.

The two Shiffman et al studies were a large patch $(n=2636)$ and gum $(n=3155)$ study reported together in a single paper. ${ }^{32}$ These were non-randomised studies in which single group, open label prospective trials of OTC gum and of OTC patch were conducted and their results at six weeks and six months compared to those obtained in surveys of smokers who had obtained gum and patch via prescription. The major advantage of this design was that the prescription arm was a true "real world" comparison-that is, subjects received prescription from their own physician, not a trained research physician in the study. The major disadvantage of this design is the lack of randomisation. This was minimised to some extent by using logistic regression to adjust for differences in the groups in age, sex, cigarettes/day, etc. The prescription surveys were done by having a large chain store search its records for individuals with a prescription for patch or gum approximately six weeks or six months ago. Purchasers were sent an invitation to call a toll-free number to participate in a survey "of pharmacy services" (that is, no mention of smoking or NRT) for \$20. The survey then asked not only about pharmacy services but also NRT use and smoking status. In these arms, the physician determined the dose of gum or patch. In 
Table 3 Studies of OTC NRT versus prescription NRT

\begin{tabular}{lllllll}
\hline Study & Product & $\mathrm{n}$ & Randomised & Visits & $\begin{array}{l}\text { Follow up } \\
\text { (months) }\end{array}$ & Outcome \\
\hline Korberly et $a^{\beta 3}$ & Patch & 3235 & Yes & 5 & 12 & $\begin{array}{l}\text { Biochemical } \\
\text { verification }\end{array}$ \\
Leischow et $a^{\beta 4}$ & Patch & 300 & Yes & 5 & 12 & Continuous abstinence \\
Shiffman et $a^{\beta 2}$ & Patch & 2636 & No & 6 & 6 & Yes \\
Shiffman et $a^{\beta 2}$ & Gum & 3136 & No & 6 & 6 & Continuous abstinence \\
\hline
\end{tabular}

Table 4 OTC NRT versus prescription NRT

\begin{tabular}{lllll}
\hline Study & $\begin{array}{l}\text { Abstinent with } \\
\text { OTC }\end{array}$ & $\begin{array}{l}\text { Abstinent with } \\
\text { prescription }\end{array}$ & $\begin{array}{l}\text { Unadjusted OR } \\
(95 \% \mathrm{Cl})\end{array}$ & $\begin{array}{l}\text { Unadjusted OR } \\
(95 \% \mathrm{Cl})\end{array}$ \\
\hline Korberly et $a^{\beta 3}$ & $169 / 1721$ & $146 / 1514$ & $1.0(0.8$ to 1.3$)$ & \\
Leischow et $a^{\beta 4}$ & $1 / 149$ & $3 / 151$ & $0.3(0.0$ to 3.2$)$ & $1.4(0.7$ to 2.6$)$ \\
Shiffman et $a^{\beta 2}$ (gum) & $252 / 2981$ & $12 / 155$ & $1.1(0.6$ to 2.0$)$ & 1.6 (1.7) to 7.6$)$ \\
Shiffman et $a^{\beta 2}$ (patch) & $217 / 2367$ & $8 / 269$ & $3.3(1.6$ to 6.7) & 3.6 (1.7 \\
\hline
\end{tabular}

the OTC arms the package label advised subjects use $4 \mathrm{mg}$ if they smoked more than 25 cigarettes/day via the package label but self selected their dose. The doses of patch for prescription and OTC arms were similar; however, $6 \%$ in the prescription arm were prescribed $4 \mathrm{mg}$ by their physician whereas $60 \%$ of those in OTC arm self selected the $4 \mathrm{mg}$ dose; thus, in the gum analyses, post-hoc analyses were used to correct for this dosing difference.

\section{Meta-analysis of OTC NRT versus prescription NRT}

For the meta-analysis, the six month rates were used as they were common to all four studies and the adjusted ORs were used for the Shiffman studies. All of the studies used prolonged abstinence or continuous abstinence outcomes. An OR $\leqslant 1.0$ would indicate OTC NRT was less efficacious than prescription NRT. The ORs ranged from 0.3-3.6. (table 4, fig 2). The ORs for the two randomised trials were 0.3 and 1.1 and for the two non-randomised trials were 1.4 and 3.6. The test for homogeneity was significant $(p=0.01)$ indicating the results were heterogeneous. However, the results of the metaanalyses with and without the studies with the lowest (Leischow) or the highest (Shiffman) ORs were similar to those with all studies; thus, we report the meta-analysis of all four studies despite the heterogeneity. In the random effects meta-analysis with all studies, the overall OR was 1.4 (95\% CI 0.6 to 3.3 ). Since the $95 \%$ CIs overlapped with 1.0 , we conclude OTC and prescription NRT produced equivalent quit rates.

\section{Estimate of actual abstinence rates with OTC NRT}

To produce an estimate of the absolute quit rates at six month follow up with OTC NRT, we examined the results of the nine OTC NRT arms mentioned earlier (tables 1 and 3). As mentioned earlier, one gum study had a small sample size and was perhaps not generalisable $e^{29}$ and the longest follow up in one patch versus placebo study was 10 weeks ${ }^{27}$; thus, neither of these was used in the analysis. This left six patch studies and one gum study. Also mentioned earlier was that recent analyses suggest repeated point prevalence, continuous abstinence, and prolonged abstinence quit rates are usually similar across the definitions ${ }^{46}$; thus we combined studies using these definitions. When more than one of these types of outcome was reported in a study, we used continuous abstinence $>$ prolonged abstinence $>$ repeated point prevalence. This would produce the lowest estimated quit rate.

The quit rates from these seven studies were not homogenous $(p<0.01)$. When we removed the gum study, the quit rates among the six patch studies were still not

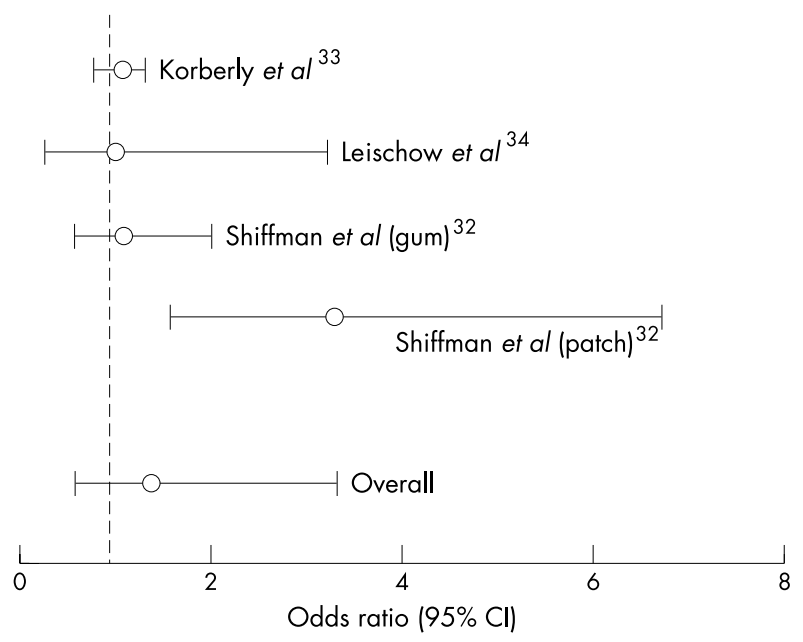

Figure 2 Odds ratio and $95 \%$ confidence interval for OTC NRT versus prescription NRT studies using intent-to-treat analysis. Note $x$ axis is not in log coordinates.

homogenous $(\mathrm{p}<0.01)$. The Leischow and Hays studies have significantly lower quit rates (weighted mean 4\%, 95\% CI 2\% to $6 \%$ ) than the other five studies (weighted mean 9\%, 95\% CI $9 \%$ to $10 \%$ ). We do not know why the quit rates were lower in the former two trials. Lower quit rates did not appear to be associated with whether a study was a placebo controlled trial, whether it was a gum or patch studies, or whether subjects in the study had to pay for medications. If all seven trials are combined using a random effects model, the mean six month quit rate is $7 \%(95 \%$ CI $4 \%$ tol $1 \%)$. If the six patch trials are combined with the random effects model, the mean six month quit rate is also $7 \%$ (95\% CI $4 \%$ to $11 \%$ ).

\section{Methodological issues}

One of the methodological concerns about OTC trials has been that the number of contacts may artificially increase the quit rates over that which would be seen in a true OTC setting. ${ }^{8}{ }^{15} \mathrm{In}$ the present data set, studies with a higher number of visits did not have higher absolute quit rates or ORs (tables 1 and 3). In addition, although there was only a small amount of variability, the minimum cigarettes/day inclusion criterion, definition of abstinence (repeated point prevalence versus continuous abstinence versus prolonged abstinence), presence of biochemical verification, patch versus gum, and source of funding did not appear to account for higher versus lower ORs. 


\section{DISCUSSION}

Our major results are: (1) NRT retains its pharmacological efficacy in the OTC setting, (2) NRT produces similar quit rates in OTC and prescription conditions; and (3) the absolute quit rate with OTC NRT is modest.

One potential limitation of our conclusions is that although there were several placebo controlled patch studies, there were only two placebo controlled studies with nicotine gum and each had methodological problems (that is, small sample size or lack of long term follow up). Also, there were no OTC trials of nicotine inhaler or tablet, both of which are currently OTC in several countries. One difference between the gum/inhaler/ tablet products and the patch is that because the former require multiple self administrations to be efficacious, their compliance appears to be lower. ${ }^{7}$ Thus, it is plausible that under OTC settings, low motivation and less instructions could result in poor compliance sufficient to prevent efficacy of nicotine gum/inhaler/tablet. ${ }^{8}{ }^{15}$ This would suggest the results obtained in our analysis of mostly patch studies might not apply to OTC gum. On the other hand, in survey studies, compliance with OTC gum and patch appears to be similar to that for prescription nicotine gum and patch (data for inhaler and tablet are not available). ${ }^{17} 2324$ In addition, the single study of OTC nicotine gum versus prescription nicotine gum in the current analysis ${ }^{27}$ found similar quit rates. These results would argue that our mostly patch results would generalise to OTC gum/inhaler/tablet. Finally, the comparison of OTC versus prescription NRT contained only two randomised trials.

Our conclusion that the pharmacological efficacy of NRT remains in an OTC setting replicates the earlier analysis of the USPHS based on three studies ${ }^{1}$ (versus four in our analysis). There is a common belief that psychosocial therapy is necessary for medications to be pharmacologically efficacious in alcohol and illicit drug dependencies, ${ }^{18}$ and some have thought the same to be true for nicotine dependence. In fact, the mean for the OR for OTC NRT versus placebo in our metaanalysis (OR 2.5, 95\% CI 1.8 to 3.6 ) is similar to that found in the two most recent meta-analyses of NRT given with some adjunct behavioural therapy (fig l: OR 1.9, 95\% CI 1.7 to 2.2; and OR $1.8,95 \%$ CI 1.6 to 2.0$).{ }^{12}$ Thus, our findings directly contradict the above belief and are consistent with the results of recent meta-analyses that suggest the OR for NRT versus placebo is independent of the amount of concurrent psychological treatment. ${ }^{12}{ }^{20}$ In other words, the conditions of NRT use (and other factors) appear to set the base rates for abstinence and adding NRT appears to have a multiplicative effect on this base rate. One explanation for the retention of efficacy for NRT when given without behavioural therapy is that, unlike other drug dependent persons, smokers usually do not have pressing psychosocial problems that require treatment. ${ }^{48}$ One major implication of this conclusion is that although many private and government programmes that provide NRT do so contingent upon receiving a psychosocial treatment or consulting a physician, ${ }^{49}$ our results suggest such contingencies should be removed.

Our second conclusion is that absolute quit rates were similar in OTC and prescription conditions. This finding appears to contradict the conclusions of recent meta-analyses that advice from physicians increases quit rates by a factor of 1.3-1.7. ${ }^{12}$ The increased quit rates in the prior meta-analyses may be due to inclusion of trained physicians, and their ability to motivate a quit attempt in ambivalent smokers. ${ }^{50} 51$ In contrast, in the OTC trials, physicians were not trained and smokers were already motivated to quit.

Our third conclusion is that the average six month quit rate with OTC NRT is modest. The 7\% long term quit rate we report is similar to the prior estimated rate of long term quitting with OTC NRT of $8 \% .^{52}$ These OTC long term quit rates are lower than those reported in recent meta-analyses of gum, patch or psychosocial therapies when given with more intensive

\section{What this paper adds}

The US Public Health Service guideline concluded over-the-counter (OTC) nicotine replacement therapy (NRT) is efficacious for smoking cessation. However, some still question whether medications can be effective without counselling. Meta-analyses of randomised controlled clinical trials is widely recognised as a more valid method to decide on effectiveness than uncontrolled studies, surveys of self selected treatment seekers, etc.

This meta-analysis of newer studies concludes that OTC NRT is pharmacologically effective and produces quit rates similar to those seen when nicotine replacement is used in typical medical practice. Although the absolute quit rates with OTC NRT are modest, OTC NRT more than doubles the odds of successful quitting, and, because of its wide availability and ease of access, this intervention still has a substantial public health impact.

interventions. ${ }^{125354}$ (Note we are referring to absolute quit rates, not ORs here.) The most likely explanations for the higher quit rates in the prior meta-analyses are that subjects in their studies: (a) did not have to pay for treatment, (b) often received concurrent behavioural therapy, (c) had expert therapists, and (d) were more motivated. Thus, a comparison of quit rates in our OTC meta-analysis and prior meta-analysis is a comparison of "apples and oranges". As importantly, the conditions in the prior analyses occur only rarely in the real world, whereas the conditions in our OTC studies are common.

Perhaps a better comparator for the OTC quit rates is the outcome of self quitting. The only meta-analysis of self quitting reported a long term quit rate of $6 \% .{ }^{55}$ The studies in this meta-analysis were done in the 1980s. Since then, quit rates appear to be falling at about $1.3 \%$ per year, ${ }^{56}$ perhaps because of a "hardening" among remaining smokers. ${ }^{57}$ Consistent with this observation, a subsequent self quitting study in 1992 reported a long term quit rate of 3\%. ${ }^{58}$ Thus, the quit rates among self quitters during the late 1990s when the above OTC NRT studies were done was probably near 3\%. If so, the $7 \%$ quit rate with OTC may represent a substantial increase over self quitting.

\section{Conclusion}

This meta-analysis focuses on the efficacy of OTC NRT. Other concerns about OTC NRT such as abuse liability, undermining of future quit attempts, and limited access among underserved smokers have been addressed in other reviews. ${ }^{68}{ }^{15} 59$ In our opinion, the evidence allays these concerns. ${ }^{6}$

Another concern is effectiveness of OTC NRT when used by the consumer. ${ }^{915}{ }^{17}$ One method to examine this concern has been to determine whether the abstinence rate in smokers who elect to use OTC NRT in a quit attempt is higher than that in smokers who do not use NRT. ${ }^{17}$ Although this comparison concluded OTC NRT is not effective in the "real world", we believe this conclusion is premature for four reasons. Firstly, smokers who elect to use OTC NRT are more dependent than those who do not elect to use NRT and thus the comparison is biased. Secondly, the major plausible mechanism for why OTC NRT would not be effective in the real world would be that compliance is very low. However, compliance in surveys of consumers using OTC $\mathrm{NRT}^{17}$ appears to be similar to that reported in the OTC trials reviewed above. Thirdly, although we have labelled the OTC trials as "efficacy" trials, they are essentially effectiveness trials in that they imposed almost no exclusion criteria, recruited from non-medical sites, had sample characteristics similar to self quitters, required smokers to pay for the product, induced very small study burdens, had no face-to-face interventions, and so on. Fourth and most importantly, typically data from experimental studies is assumed to be more valid than that from correlation studies. 
The public health impact of an intervention is the product of its effectiveness and utilisation. ${ }^{12}$ In the USA, national sales data $^{5960}$ and national surveys ${ }^{21}$ suggest switching NRT from prescription to OTC has substantially increased use of NRT and quit attempts (however, the OTC switch may not have increased NRT use or quit attempts in states with pre-existing aggressive tobacco control programmes $\left.{ }^{13}{ }^{21}{ }^{61}\right)$. Increased utilisation with OTC availability is beneficial if it is not offset by a loss of efficacy. Our meta-analysis concludes OTC NRT is efficacious and there has been no significant loss of efficacy.

\section{ACKNOWLEDGEMENTS}

Supported by US National Institute on Drug Abuse Senior Scientist Award DA-00490 (JRH). Dr Hughes has received speaking and consulting fees and grants from Glaxo-SmithKline and Pharmacia, both of whom market nicotine replacement products, as well as from other companies/organisations that provide smoking cessation services and products. Dr Shiffman serves as a consultant to GlaxoSmithKline Consumer Healthcare (GSKCH) on an exclusive basis regarding matters relating to smoking cessation. Dr Shiffman has a financial interest in a venture to develop new nicotine medications. We thank the authors of the trials that commented on our manuscript.

\section{Authors' affiliations}

J R Hughes, Department of Psychiatry, University of Vermont, Burlington, Vermont, USA

S Shiffman, Pinney Associates and the University of Pittsburgh,

Pittsburgh, Pennsylvania, USA

P Callas, J Zhang, Medical Biostatistics, University of Vermont

\section{REFERENCES}

1 Fiore MC, Bailey WC, Cohen SJ, et al. Treating tobacco use and dependence. Clinical Practice Guideline. Rockville, Maryland: Public Health Service, 2000

2 Silagy C, Mant D, Fowler G, et al. Nicotine replacement therapy for smoking cessation (Cochrane Review). Oxford: Update Software, The Cochrane Library, Issue 5, 2000.

3 Gallup Organization. Attitudes and behaviors related to smoking cessation. New York, Gallup Organization, August 1999.

4 Lichtenstein EH., Ollis JF. Patient referral to a smoking cessation program: who follows through? J Family Practice 1992;34:739-44.

5 Burton SL, Kemper KE, Baxter TA, et al. Impact of promotion of the Great American Smokeout and availability of over-the-counter nicotine medications, 1996. MMWR Morb Mortal Wkly Rep 1997;46:867-71

6 Hughes JR. The effectiveness of over-the-counter nicotine replacement: a rebuttal. Drug and Alcohol Review 2001;20:319-24.

7 Hughes JR, Goldstein MG, Hurt RD, et al. Recent advances in the pharmacotherapy of smoking. JAMA 1999;281:72-6.

8 Leischow S, Ranger-Moore J, Major J. OTC nicotine replacement effectiveness: a glass half empty or half full? Presented at the Annua Meeting of The Society for Research on Nicotine and Tobacco, Seattle, Washington, March 2001

9 McNagny SE, Ahluwalia JS. Use of over-the-counter nicotine patch for smoking cessation: prudent or premature? JAMA 1996;276:371-2.

10 Ontario Medical Association. Rethinking stop-smoking medications: myths and facts. Ontario, Canada: Ontario Medical Association, Health Policy Department, 1999

11 Pierce JP, Gilpin E, Farkas AJ. Nicotine patch use in the general population: results from the 1993 California Tobacco Survey. J Natl Cancer Inst 1995;87:87-93.

12 Shiffman S, Mason KM, Henningfield JE. Tobacco dependence treatments: review and prospectus. Annu Rev Public Health 1998; 19:335-58.

13 Thorndike AN, Biener L, Rigotti NA. The impact on smoking cessation of switching nicotine replacement therapy to over-the-counter status. Am J Public Health 2002;19:437-42.

14 Center for Disease Control and Prevention. Use of FDA-approved pharmacologic treatments for tobacco dependence - United States, 1984-1998. MMWR Morb Mortal Wkly Rep 2000;49:665-8.

15 Walsh RA, Penman AG. The effectiveness of nicotine replacemen therapy over-the-counter. Drug and Alcohol Review 2000;19:243-7.

16 Walsh RA, Penman AG. The effectiveness of nicotine replacement therapy over-the-counter: reply to Hughes. Drug and Alcohol Review 2001;20:319-24.

17 Pierce JP, Gilpin EA. Impact of over-the-counter sales on effectiveness of pharmaceutical aids for smoking cessation. JAMA 2002;288:1260-4.

18 National Institute on Drug Abuse. Principles of drug addiction treatment. Washington DC: National Institutes of Health, 1999

19 Onken LS, Blaine JD, Boren JJ. Integrating behavioral therapies with medications in the treatment of drug dependence. National Institute on Drug Abuse Research Monograph 150. Rockville, Maryland: US Department of Health and Human Services, National Institute on Drug Abus,. 1995
20 Hughes JR. Combining behavioral therapy and pharmacotherapy for smoking cessation: an update. In: Onken, LS, Blaine JD, Boren JJ, eds. Integrating behavior therapies with medication in the treatment of drug dependence. NIDA Research Monograph 150. Washington DC: National Institute on Drug Abuse, 1995:92-109.

21 Gitchell JG, Di Marino ME, Rohay JM et al. Population trends in smoking cessation and correlations to pharmacotherapy utilization: results from the current population survey. Paper presented at the Annual Meeting of the Society for Research on Nicotine and Tobacco, Savannah, Georgia, 22 February 2002.

22 Swartz SH, Ellsworth AJ, Curry SJ, et al. Community patterns of transdermal nicotine use and provider counseling. J Gen Intern Med 1995; 10:656-62

23 Sinclair HK, Bond CM, Lennox AS, et al. Nicotine replacement therapies: smoking cessation outcomes in a pharmacy setting in Scotland. Tobacco Control 1995:4:338-43.

24 Shiffman S, Hughes JR, DiMarino ME, et al. Extended treatment with over-the-counter nicotine gum in the real-world. Paper presented at the World Congress on Smoking or Health. Chicago, August 2000.

25 Johnson RE, Hollis JF, Stevens VJ, et al. Patterns of nicotine gum use in a health maintenance organization. Ann Pharmacother 1991;25:730-5.

26 Johnson RE, Stevens VJ, Hollis JF, et al. Nicotine chewing gum use in the outpatient care setting. J Family Practice 1992;34:61-5.

27 Shiffman S, Gorsline J, Gorodetzky CW. Efficacy of over-the-counter nicotine patch. Nicotine and Tobacco Research 2002;4:477-83.

28 Davidson M, Epstein M, Burt R, et al. Efficacy and safety of an over-the-counter transdermal nicotine patch as an aid for smoking cessation. Arch Family Med 1998;7:569-74.

29 Schneider NG, Jarvik ME, Forsythe $A B$, et al. Nicotine gum in smoking cessation: a placebo-controlled double-blind trial. Addictive Behaviors 1983;8:253-61

30 Sonderskov J, Olsen J, Sabroe S, et al. Nicotine patches in smoking cessation: a randomized trial among over-the-counter customers in Denmark. Am J Epidemiol 1997;145:309-18.

31 Hays JT, Croghan IT, Schroeder DR, et al. Over-the-counter nicotine patch therapy for smoking cessation: Results from randomized double-blind, placebo-controlled, and open label trials. Am J Public Health 1999:89:1701-7.

32 Shiffman S, Rolf CN, Gorsline J, et al. Real-world efficacy of prescription and over-the-counter nicotine replacement therapy. Addiction 2002;97:505-16

33 Korberly BH, Epstein MS, Maguire MK, et al. Over-the-counter efficacy of a $15 \mathrm{mg} / 16$ hour nicotine patch for smoking cessation: a randomized, multicenter trial. Presented at the annual meeting of the Society for Research on Nicotine and Tobacco, New Orleans, March 1999.

34 Leischow SJ, Muramoto ML, Cook GN, et al. OTC nicotine patch effectiveness alone and with brief physician intervention. Am J Health Behavior 1999:23:61-9.

35 Leischow S, Cook G, Muramoto ML. Studies on the efficacy of nicotine patch, inhaler and gum in an OTC setting. Presented at the Annual Meeting of The Society For Research on Nicotine and Tobacco. San Diego, California, March 1999.

36 Leischow S, Cook G, Muramoto M. Nicotine gum: does cost affect quit rates?, Paper presented at annual meeting of the College on Problems of Drug Dependence, Acapulco, Mexico, June 1999.

37 Humfleet G, Hall SM, Sees KL, et al. Brief versus extended smoking treatment: Preliminary findings. Presented at the Annual Meeting of The Society for Research on Nicotine and Tobacco, Seattle, Washington, March 2001

38 Cinciripini PM, Lapitsky L, Seay S, et al. The effects of smoking schedules on cessation outcome: can we improve on common methods of gradual and abrupt nicotine withdrawal? J Consult Clin Psychol 1995:63:388-99.

39 Hughes JR, Wadland WC, Fenwick JW, et al. Effect of cost on the self-administration and efficacy of nicotine gum: a preliminary study. Prev Med 1991;20:486-96

40 Dey P, Foy R, Woodman $M$, et al. Should smoking cessation cost a packet? A pilot randomized controlled trial of the cost-effectiveness of distributing nicotine therapy free of charge. $\mathrm{Br} J$ General Practice 1999:49:127-8

41 Benowitz N, Jacob III P, Ahijevych K, et al. Biochemical verification of tobacco use and cessation. Nicotine and Tobacco Research 2002;4:149-59.

42 Velicer WF, Prochaska JO, Rossi JS, et al. Assessing outcome in smoking cessation studies. Psychological Bulletin 1992;111:23-41.

43 Fleiss JL. Statistical methods for rates and proportions. New York: John Wiley \& Sons, 1981

44 Shadish WR, Haddock CK. Combining estimates of effect size. In: Cooper $\mathrm{H}$, Hedges LV, eds. The handbook of research synthesis. New York: Russell Sage Foundation, 1994:261-81.

45 Velicer WF, Prochaska JO. A comparison of four self-report smoking cessation outcome measures. Addictive Behaviours (in press).

46 Keely JP, Hughes JR, Carpenter M. A method to convert prolonged abstinence and point prevalence quit rates. Nicotine and Tobacco Research 2001;3:272-3.

47 Glynn TJ, Manley MW. How to help your patients stop smoking. Washington: US Govt Printing Office, 1989

48 Hughes JR. Psychiatric comorbidity. Nicotine and Tobacco Research 1999;1:S149-52.

49 Schauffler HH, Mordavsky J, Barker D, et al. State Medicaid coverage for tobacco-dependence treatments - United States, 1998 and 2000. MMWR Morb Mortal Wkly Rep 2001;50:979-82 
50 Thorndike AN, Rigotti NA, Stafford RS, et al. National patterns in the treatment of smokers by physicians. JAMA 1998;279:604-8.

51 Russell MA, Stapleton JA, Feyerabend C, et al. Targeting heavy smokers in general practice: randomized controlled trial of transdermal nicotine patches. BM 1993;306:1308-12.

52 Winchell C, Wright C, Burke L, et al. Long-term abstinence in users of OTC nicotine replacement. Clin Pharmacol Therapeutics 1997;61:191.

53 Lancaster T, Stead LF. Individual behavioural counseling for smoking cessation. The Cochrane Library. Issue 3. Oxford: Updated Software, 2002

54 Stead LF, Lancaster T. Group behavior therapy programmes for smoking cessation. The Cochrane Library. Issue 3. Oxford: Updated Software, 2002

55 Cohen S, Lichtenstein E, Prochaska JO, et al. Debunking myths about self-quitting. Am Psychol 1989:44:1355-65.

56 Irvin JE, Brandon TH. The increasing recalcitrance of smokers in clinical trials. Nicotine and Tobacco Research 2000;2:79-84.
57 Hughes JR. The evidence for hardening. Is the target hardening? $\mathrm{NCl}$ Smoking and Tobacco Control Monograph. Rockville, Maryland: National Cancer Institute (in press).

58 Hughes JR, Gulliver SB, Fenwick JW, et al. Smoking cessation among self-quitters. Health Psychol 1992;11:331-4

59 Shiffman S, Gitchell JG, Pinney JM, et al. Public health benefit of over-the-counter nicotine medications. Tobacco Control 1997;6:306-10

60 Hughes JR, Burns DM. Impact of medications on smoking cessation. In: Population based smoking cessation: proceedings of a conference on what works to influence cessation in the general population. Smoking and Tobacco Control Monograph No. 12. Bethesda, Maryland: National Cancer Institute, 2001:155-64

61 Major JM, Burns DM. Use of nicotine replacement therapy in California. Paper presented at the Annual Meeting of the Society for Research on Nicotine and Tobacco, Savannah Georgia, 21 February 2002.

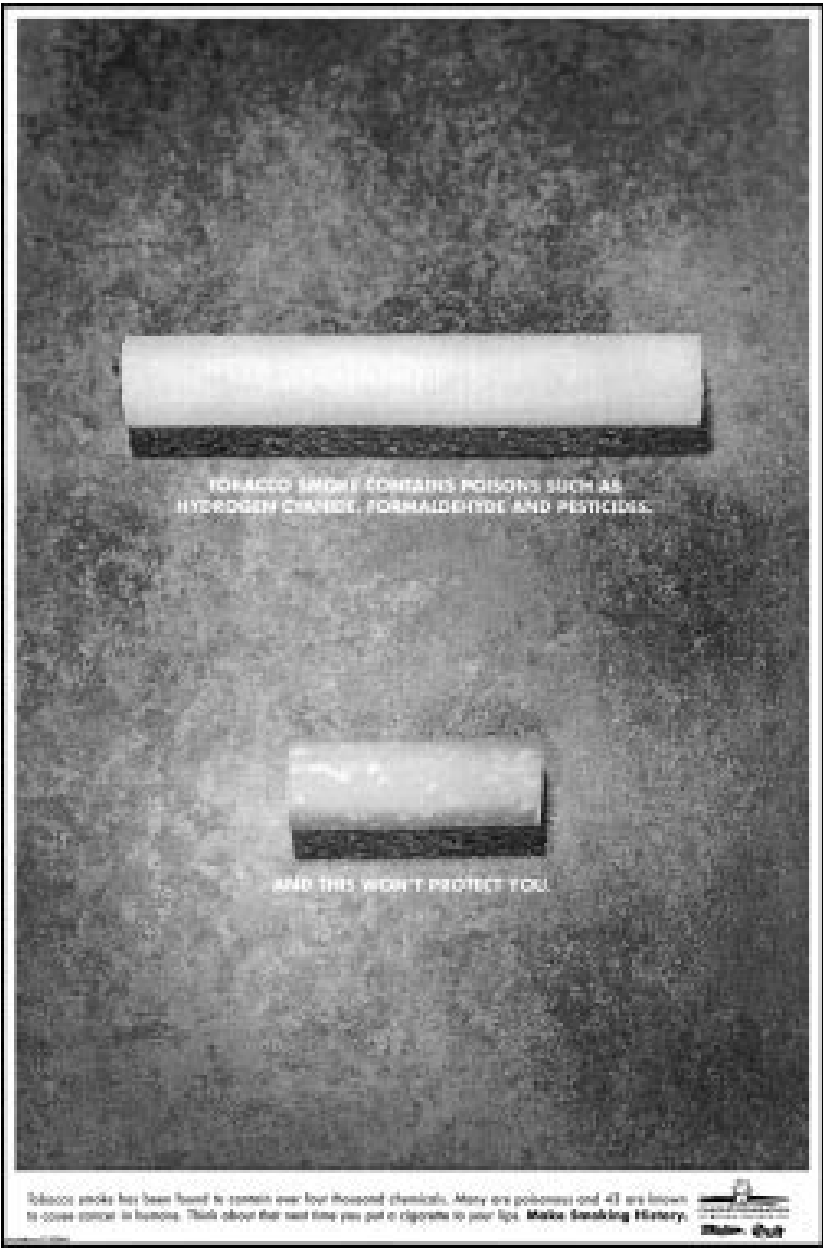

Reproduction courtesy of Cancer Foundation of Western Australia, Healthway and Quit. 